\title{
ATMOSPHERIC EFFECTS ON FREE SPACE EARTH-TO-SATELLITE OPTICAL LINK IN TROPICAL CLIMATE
}

\author{
Norhanis Aida M.Nor*, Md. Rafiqul Islam, Wajdi Al-Khateeb, Suriza A. Z. \\ Department of Electrical and Computer Engineering, Faculty of Engineering, \\ International Islamic University Malaysia (IIUM), \\ 53100 Kuala Lumpur, Malaysia

\begin{abstract}
Free Space Optic (FSO) vulnerability towards atmospheric phenomena is becoming a main issue towards its implementation. A lot of studies have been conducted to estimate the climatological effects on FSO links but most of them are based on terrestrial link with short path lengths and centred in temperate regions. Hence, this paper aims to analyse the performance of FSO links from earth-to-LEO satellite in tropical regions where rain and haze are the main concerns. This analysis is based on available methods and data to predict earth-to-satellite FSO links with the scaled up data from the measurement on terrestrial FSO link installed at International Islamic University Malaysia (IIUM) Kuala Lumpur campus. Data collected from terrestrial link are FSO received signal levels, corresponding rain intensity and visibility variations. The measured data are scaled up to the effective distance of slant path lengths and then compared with the predicted values. These findings will be very useful for FSO earth-space communication link designers and can be as a benchmark of FSO system design.
\end{abstract}

\section{KEYWORDS}

Free Space Optic (FSO), rain attenuation, rain intensity, haze attenuation, availability

\section{INTRODUCTION}

Free Space Optic (FSO) or often known as "fiberless optics" or "optical wireless" is an emerging technology that has a great chance to complement the traditional wireless communications. FSO is actually an alternative method of transmitting informationfrom one place to another by sending pulsed of light in Terahertz spectrum. The concept of FSO is essentially same as fiber optic transmission and the only difference is the transmission channel where FSO is using air rather than being guided through an optical cable. FSO is become an optimal solution for last-mile connection because of the capability in transmitting higher speed of data which is up to $2.5 \mathrm{Gbps}$.

There are several significant advantages offered by FSO especially easily deployment by saving time and cost as well as does not require any frequency authorization or any specific license[1]. To further enhance the application of FSO, laser communications to space is essential in order to have higher speed of global connections. Nevertheless, FSO has a very crucial drawback which is highly attenuated by atmospheric phenomena. Result shows in [2] done in temperate region stated that in heavy fog conditions, attenuation may raise up to $300 \mathrm{~dB} / \mathrm{km}$. 
Meanwhile, the climatological phenomena in tropical regionsare dominated by rain and haze as it occurs almost year-round. In addition, most of the researches are centring on terrestrial links. Generally, FSO link can be achieved successfully for short distance link due to lower atmospheric attenuationand accurate line-of-sight link. There are very limited studies for FSO earth-to-space link in tropical region as the attenuation expected to be higher for longer FSO links especially to implement it in space.

Optical technologies for satellite networks are expected to revolutionize space system architectures [3]. There are few successful experiment for space FSO has been achieved such as Ground-to-OrbiterLasercom Demonstration (GOLD) and Semiconductor Laser Intersatellite Link Experiment (SILEX) [4]. Those experiments proved the operability of long distance FSO especially from ground to space. Therefore, this paper is aiming to provide feasible analysis of performing FSO from earth-to-satellite especially Low Earth Orbit (LEO) satellite by quantifying several atmospheric phenomena occur in tropical region that will degrade the performance of the link. The phenomena includegeometrical attenuation, absorption, scintillation, haze attenuation, and rain attenuation. Analysis will consist of simulation of prediction models derived from the integration of FSO terrestrial and microwave earth-to-satellite link and the data from the experimental works.

The rest of the paper is organized as follows. Section II will describe about the main parameters of FSO which is link margin and environmental phenomena that will affect FSO link. Section III elaborates the experimental setup that is used to get the real data of rain, haze, and FSO link. Then, section IV discusses the simulation and experimental results as well as comparing the results. Last but not least, conclusion is presented in Section $\mathrm{V}$ by affirming the feasibility of performing FSO link from earth-to-satellite.

\section{PERFORMANCE EVALUATION OF FSO EARTH-TO- SATELLITE LINK}

This section describes the mathematical modelling used to evaluate the performance of FSO link and determine each type of loss occurs along the propagation from earth-to-satellite.

\subsection{Link Margin and Link Availability}

Link Margin determines how well a FSO link will perform. It predicts how much margin, or extra power will be available in a link under any particular set of operating conditions [5] either affected or unaffected by atmospheric conditions. The calculation is essential to design an acceptable system. It is determined by subtracting all losses that occur during data transmission including receiver sensitivity, $S_{r}(\mathrm{dBm})$ by optical transmit power, $P_{t}(\mathrm{dBm})$. The losses containing the losses from atmosphere which are absorption, $A_{s}(d B)$, scintillation, $A_{\text {scin }}(d B)$, rain attenuation, $A_{\text {rain }}(d B)$ and haze attenuation, $A_{\text {haze }}(d B)$ as well as the losses from the system itself, $A_{\text {system }}(d B)$ and geometrical attenuation, $A_{G e o}(d B)$. Eq. (1) shows the calculation[6]. Receiver sensitivity is the minimum amount of optical energy that must be received by the FSO system for a specified error rate [5].

$M_{\text {link }}(d B)=P_{t}-S_{r}-A_{G e o}-A_{s}-A_{\text {scin }}-A_{\text {haze }}-A_{\text {rain }}-A_{\text {system }}$

Another important parameter to predict the performance of any communication link design is link availability and it is defined as the probability that the system works correctly at the time [2]. Furthermore, link availability it is very dependent on local atmospheric conditions. 


\subsection{Geometrical Attenuation}

Geometrical attenuation is the loss occurs due to spreading of the transmitted beam between the transmitter and the receiver. Normally, this is because of beam spreads to a size larger than the receiver aperture and as a result not entire light beam hits the receiver and some of the signal is lost. This loss is very dependent on the link distance (d) in $\mathrm{km}$, beam divergence angle $(\varphi)$ in $\mathrm{mrad}$, radius of receiver area (r) in $\mathrm{m}$ as stated in Eq. (2) [6].

$A_{g e o}=10 \log _{10}\left(\frac{\frac{\pi}{4}(d \cdot \varphi)^{2}}{\pi r^{2}}\right)$

Based on the equation, the effect of beam divergence angle is analysed. For LEO distance, $d$ is fixed to $750 \mathrm{~km}$ but will be varied based on the elevation angle, $\theta$ by following the equation below,

$L=\frac{L^{\prime}}{\sin \theta}$

Fig. 1 illustrated geometrical attenuation for different values of $\varphi$ ranging from $0.01 \mathrm{mrad}$ till 5 mrad with respect to different elevation angles. Here, $r$ is assumed to be equal to $0.16 \mathrm{~m}$, same with the radius of FSO equipment used. The figure shows that geometrical attenuation reduces when $\theta$ increases and $\varphi$ decreases. As instances, at $\theta=70$ degree and $\varphi=0.1 \mathrm{mrad}, \mathrm{A}_{\mathrm{Geo}}$ is equal to $47.94 \mathrm{~dB}$. Compare to when $\theta=20$ degree and $\varphi=2 \mathrm{mrad}, \mathrm{A}_{\mathrm{Geo}}$ is little bit higher which is 82.74 dB.

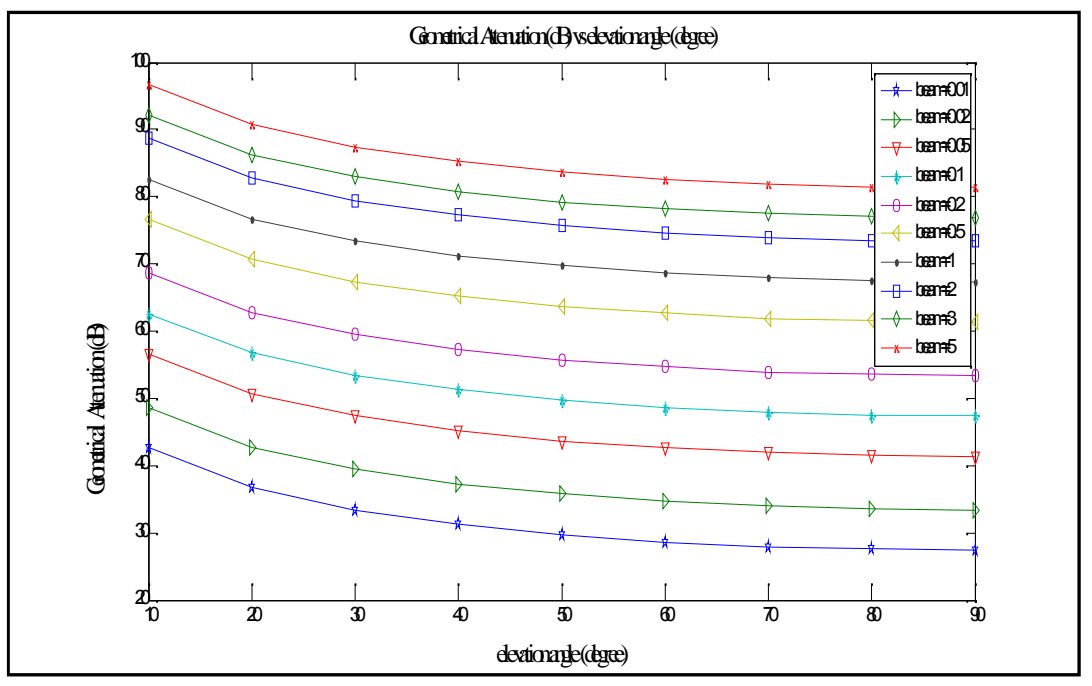

Figure 1: Geometrical Attenuation (dB) versus Elevation Angles (degree) for various beam divergence angles

\subsection{Absorption}

Absorption results from an interaction between optical radiation and the atoms and molecules of the medium for example $\mathrm{N}_{2}, \mathrm{H}_{2}, \mathrm{H}_{2} \mathrm{O}, \mathrm{CO}_{2}$, and $\mathrm{O}_{2}$ and its strength is dependent on temperature and pressure. According to [7], absorption along Earth-space paths can be calculated for the frequency between $150 \mathrm{THz}$ and $375 \mathrm{THz}$ by using Eq. (4). 
$\mathrm{A}_{\mathrm{s}}=\frac{4.3429 \tau^{\prime}}{\sin (\theta)} \mathrm{dB}$

where $\tau^{\prime}$ is the extinction ratio from height of the earth station above mean sea level, $h_{E}$ to $\infty$. However, [8] stated that the wavelength used in FSO are basically chosen to coincide the atmospheric transmission windows resulting the contributions of absorption coefficient is very small and can be neglected. It is proven as calculated value is not more than $5 \mathrm{~dB}$ even though wavelength is reduces to $850 \mathrm{~nm}$ as in Fig. 2.

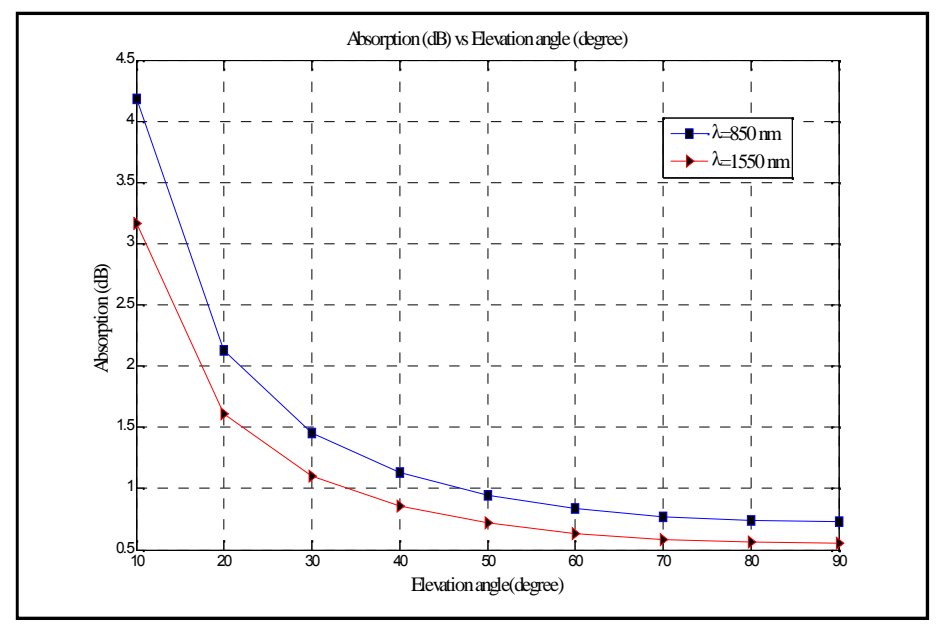

Figure 2: Absorption $(\mathrm{dB})$ vs elevation angle at $\lambda=850 \mathrm{~nm}$ and $1550 \mathrm{~nm}$

\subsection{Scintillation}

Scintillation caused by small-scale fluctuations in the refraction index of the atmosphere present along the propagation path. The amount of scintillation can be varied depend on the weather conditions of the day, with the most severe effects around midday. ITU-R [9] has publicized the general model to calculate the scintillation for vertical or slant path link as presented in Eq. 5 which based on Hufnagel-Valley (HV5/7) model. The most critical parameter in characterizing the scintillation effect is $\mathrm{C}_{\mathrm{n}}^{2}$ or also called strength of turbulence or turbulence structure parameter $\left(\mathrm{m}^{-2 / 3}\right)$. Other dependent parameter is height earth station above ground level, $\mathrm{h}_{\mathrm{o}}(\mathrm{m})$, wavelength, $\lambda(\mathrm{m}), \theta$ (degree), and effective height of the turbulence, $\mathrm{Z}(\mathrm{m})$ which typically equivalent to 20 $000 \mathrm{~m}$.

$\sigma_{\mathrm{E}-\mathrm{S}}^{2}=\sigma_{\mathrm{dBN}}^{2}=\frac{3.622 \times 10^{9} \int_{\mathrm{h}_{\mathrm{o}}}^{\mathrm{Z}} \mathrm{C}_{\mathrm{n}}^{2}(\mathrm{~h})\left(\mathrm{h}-\mathrm{h}_{\mathrm{o}}\right)^{5 / 6} \mathrm{dh}}{\lambda^{7 / 6 \sin ^{11} / 6 \theta}} \mathrm{dB}^{2}$

However, experiments have verified that the variance of log-irradiance on earth-to-space path, $\sigma_{E-S}^{2}$, will remain small which is less than $4 \mathrm{~dB}$ and there is a low probability of exceeding this limit. Though, the calculation is still carried on in order to have a comprehensive link margin value as shown in Fig. 3. The figure validates the scintillation is really small where at 10 degree elevation angle, scintillation is about $1.5 \mathrm{~dB}$ for $\lambda=850 \mathrm{~nm}$, and reduces to $0.8 \mathrm{~dB}$ at $\lambda=1550 \mathrm{~nm}$. 


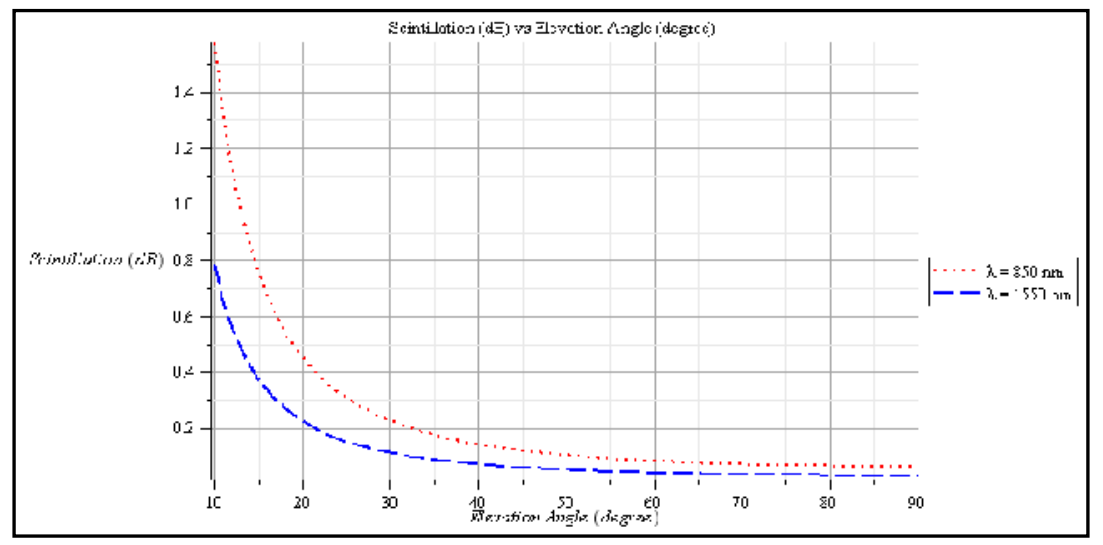

Figure 3: Scintillation (dB) vs Elevation Angle (degree) at $\lambda=850 \mathrm{~nm}$ and $1550 \mathrm{~nm}$

\subsection{Rain Attenuation}

Rain has a distance-reducing impact on FSO and it is classified under non-selective scattering since the radius of raindrop $(200-2000 \mu \mathrm{m})$ is significantly larger than the wavelength of FSO light sourcewhich make the impact is significantly less[10]. However, in tropical region like Malaysia, rain becomes a dominant factor of attenuation which cause signal degradation or even lost the communication because rainy event is experienced throughout the year which rain intensity can be exceeded than $145 \mathrm{~mm} / \mathrm{hr}$ for $0.01 \%$ of an average year[11]. According to [12], when measurements of rain attenuation on a terrestrial path were compared with the rain rate measured on the path, it was observed that the specific attenuation $(\mathrm{dB} / \mathrm{km})$ could be well approximately by

$\mathrm{A}_{\text {rain }}=\mathrm{kR}^{\alpha} \quad \mathrm{dB} / \mathrm{km}$

where $\mathrm{R}$ is the rain rate in $\mathrm{mm} / \mathrm{hr}$, and $\mathrm{k}$ and $\alpha$ are frequency and temperature dependent given by Carbonneau[13] as 1.076 and 0.67 respectively. These values will be used to determine the longterm statistic of the slant path rain attenuation by following the step mentioned in [14] used for microwave earth-to-satellite link prediction models. Fig. 4 demonstrates the relationship between rain attenuation and rain intensity for one kilometre link. As seen in the figure, rain attenuation will increase with the increment of rain intensity. For example, at $\mathrm{R}=150 \mathrm{~mm} / \mathrm{hr}$, rain attenuation is $30 \mathrm{~dB} / \mathrm{km}$ and therefore attenuation would be expected higher for earth-to-satellite link.

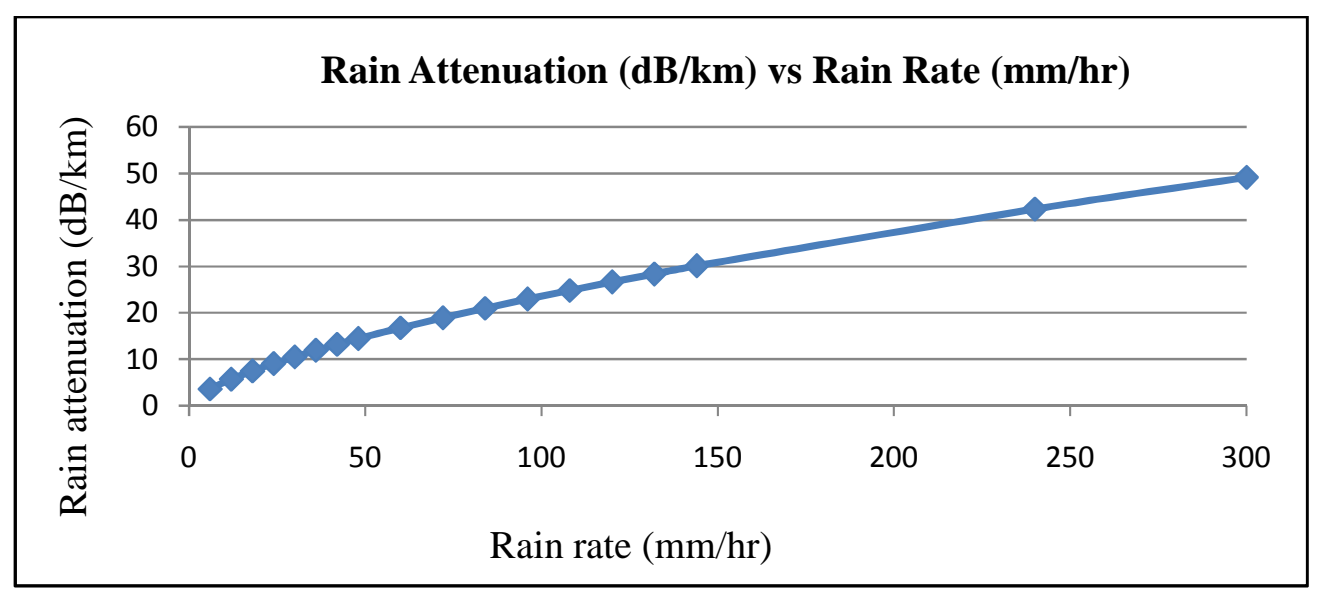

Figure 4: Rain attenuation $(\mathrm{dB} / \mathrm{km})$ vs rain intensity $(\mathrm{mm} / \mathrm{hr})$ 


\subsection{Haze Attenuation}

Haze is caused by particulate matter from many sources including smoke, road dust, and other particles emitted directly into the atmosphere, as well as particulate matter formed when gaseous pollutants react in the atmosphere. Haze particles are classified under Mie Scattering effect and main variable to determine haze attenuation is visibility range. Visibility can be defined as maximum distance that the visible $550 \mathrm{~nm}$ signal can travel while distinguishing between the target object and its background at $2 \%$ contrast [15]. Haze attenuation can be estimated using exponential Beers-Lambert law and combined it with the extinction coefficient, $\sigma$ given in [1] as in Eq. (7). The parameter $\mathrm{q}$ is a factor which depends on the scattering particle size distribution and Kim model is referred [16].

$$
A_{\text {haze }}=10 \log _{10} \exp ^{\left[\frac{3 \cdot 91}{\mathrm{v}}\left(\frac{\lambda}{550 \mathrm{~nm}}\right)^{-\mathrm{a}} * \mathrm{~L}\right]} \mathrm{dB}
$$

Generally, measurement done by Malaysian Meteorological Department (MMD)[17] shows that Malaysia air quality is good where visibility metre can give reading of more than $10 \mathrm{~km}$ most of the days throughout the year. However, there are some conditions where haze is become terrible which visibility dropped to less than $1 \mathrm{~km}$ in some areas of Malaysia. According to Haze-Watch Website [18] some parts of Malaysia were declared to be under the state of emergency due to high Air Pollution Index (API) with visibility less than $500 \mathrm{~m}$ in August 2005 and October 2006 due to forest fire in parts of Malaysia and Sumatra. This condition is equivalent to moderate or thick fog situation and need carefully deliberation.

\section{EXPERIMENTAL SETUP}

The FSO FlightStrata 155, Young tipping bucket rain gauge, and Sentry visibility metre sensor have been installed at E1 building,Faculty of Engineering, IIUM to measure FSO receive signal level, rain intensity, and visibility range separately.

\subsection{FSO Equipment (FlightStrata 155E)}

FSO equipment used in the experiment is FlightStrata 155E from LightPointe [19]. Two link heads are installed between rooftop of E1 building, Faculty of Engineering to Ruqayyah College, IIUM with the distance of $800 \mathrm{~m}$ away. It communicatesusingmultiple beam of infrared light which is invisible to the human eye and operates in optical wavelength. Each of the link head consists of transceiver which is a transmitter and a receiver to provide duplex or bi-directional capability. The operation starts by first link head transmits infrared light beams carrying the data from the network. The link head on the opposite side receives the beams, filters the optical signal, and places it on an optical fiber that connects with the network. The operating parameters of the FlightStrata are shown in Table 1 and the connection between the link head is presented in Fig. 5.

Table 1: FlightStrata 155E operating parameters

\begin{tabular}{|c|c|}
\hline Parameters & Description \\
\hline Wavelength & $850 \mathrm{~nm}$ \\
\hline Transmit power & $6 \mathrm{~mW}$ \\
\hline Beam Divergence & $2 \mathrm{mrad}$ \\
\hline Transmitter Lens Diameter & $2.5 \mathrm{~cm}$ each \\
\hline Receiver Lens Diameter & $8 \mathrm{~cm}$ each \\
\hline
\end{tabular}




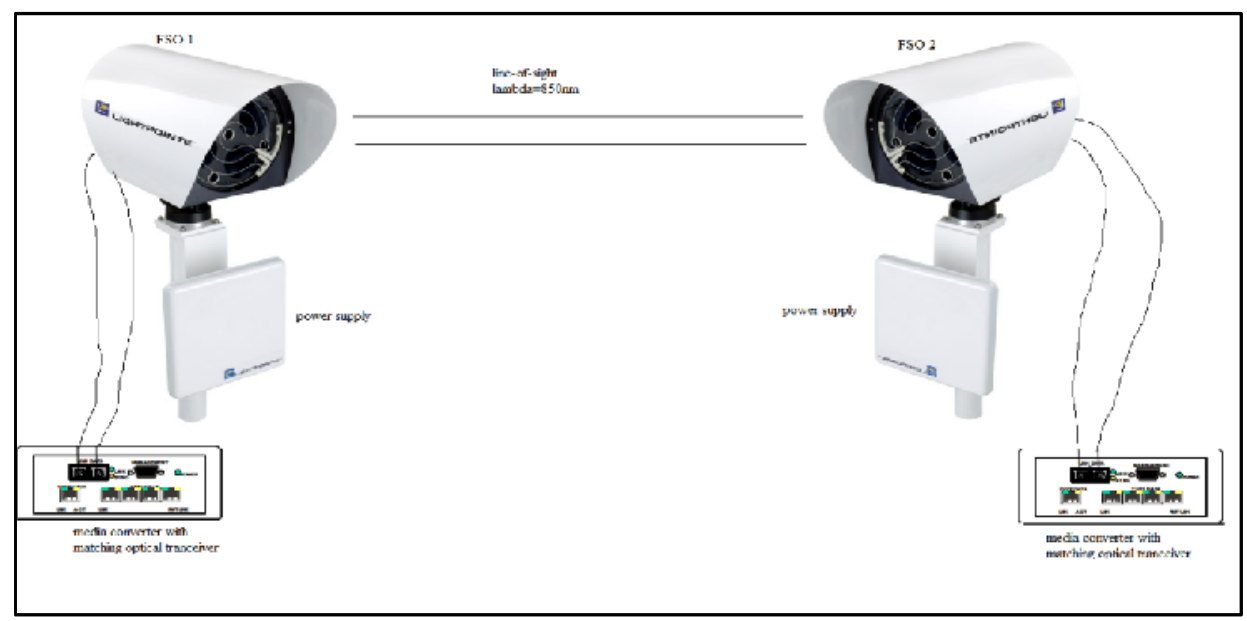

Figure 5: FSO link head connection

\subsection{Young Tipping Bucket Rain Gauge}

RM Young tipping bucket rain gauge [20] has been used to measure rain intensity by measuring $0.2 \mathrm{~mm}$ of rain water in each tip. The tipping bucket rain gauge consists of a funnel that collects the precipitation into a small seesaw-like container. When the bucket accumulates $0.2 \mathrm{~mm}$ of rain water, the weight of the water causes it to tip and empty itself. Each time a bucket tips, it sending an electrical signal, thereby enabling recording of rainfall amount with time. The rain gauge will be connected to the digital terminal of NexSensiSIC Data Logger[21]before transmitted to the iChart software as shown in Fig. 6. Since the collected data are presented in one min integration time, the rain events will be extracted and converted in $\mathrm{mm} / \mathrm{hr}$.

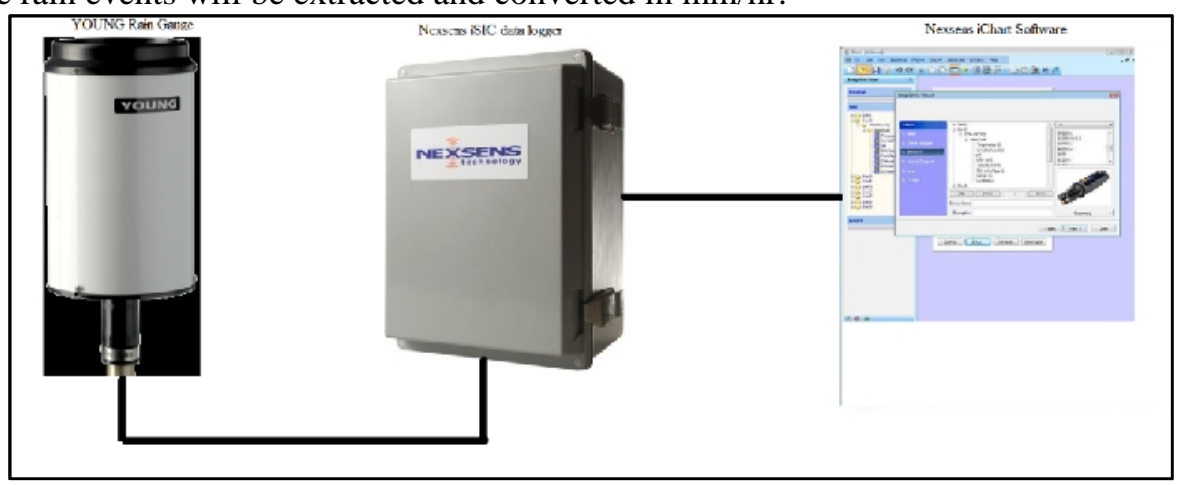

Figure 6: Rain gauge setup

\subsection{Sentry Visibility Metre Sensor}

The visibility sensor used is Sentry Visibility Sensor model SVS 1 shown in Fig. 7. It is designed to measure visibility in a variety of atmospheric conditions including fog, haze, rain, drizzle, snow, dust, and smoke. The visibility range measured is $30 \mathrm{~m}$ to $16 \mathrm{~km}$ by using $880 \mathrm{~nm}$ LED source. The measurement is based on the principle of forward scattering where infrared light projected from the transmitter intersects the field of view of the receiver with a forward angle of 42 degrees to respond to all atmospheric phenomena that reduce visibility to the human eyes.

The sensor will be connected to Sentry View Graphical user interface (GUI) that runs on a PC to automatically collect, achieve, and display visibility data in textual and graphical form. Notice 
that, the visibility range is recorded 10 second integration time which means there are six data in one minute. Hence, average of six data is calculated in order to get one min integration time as well as to calculate the cumulative distribution of visibility range in that month.

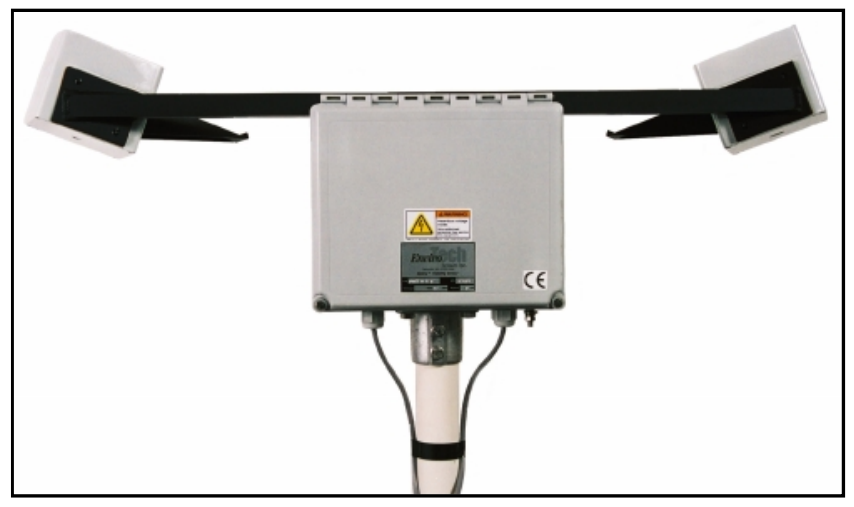

Figure 7: Sentry Visibility Sensor

\section{RESULTS AND DISCUSSION}

This section presents the results obtained from the measurement data as well as some comparison with the theoretical analysis done by using MATLAB software. The total attenuation is estimated based on two events which are during rainy events and hazy conditions. This is because rain and haze are not occurring simultaneously as rain will help to clear up the haze. According to [22], poor haze condition occurred when wind and rainfall amount were extremely low. Ultimately, based on the total attenuation, link availability and link margin are predicted for Malaysia weather conditions by obtaining cumulative distribution of measured rain intensity and visibility range. As mentioned in [23], cumulative distribution is one of most important presentation format to estimate the link availability as well as to attain the desired link performance.

\subsection{Correlation between FSO signal and Rain Intensity}

First of all, the analysis should be done to prove that rain will affect the FSO signal. Therefore, in order to relate the performance criteria of FSO link with rain intensity, it is necessary to consider any month as the period of reference. For that reason, rain intensity and FSO signal is compared for one month which is in October 2011. This analysis is important to correlate the effect of rain to the FSO link and hence one month data comparison is enough to prove the relationship. Throughout the measurement of 31 days, there are 19 events occurred but only 15 events has been measured by rain gauge but not detected by FSO link due to very low rain intensity level. The other 2 events is vice versa situation which is no rain measured by rain gauge but FSO signal is attenuated. The example of FSO input power level is shown in Fig. 8. The signal level is extracted to one minute integration time as rain gauge measure rain rate in each minute interval. Then, the time when the rains occur are match with the attenuated FSO receive signal level. 


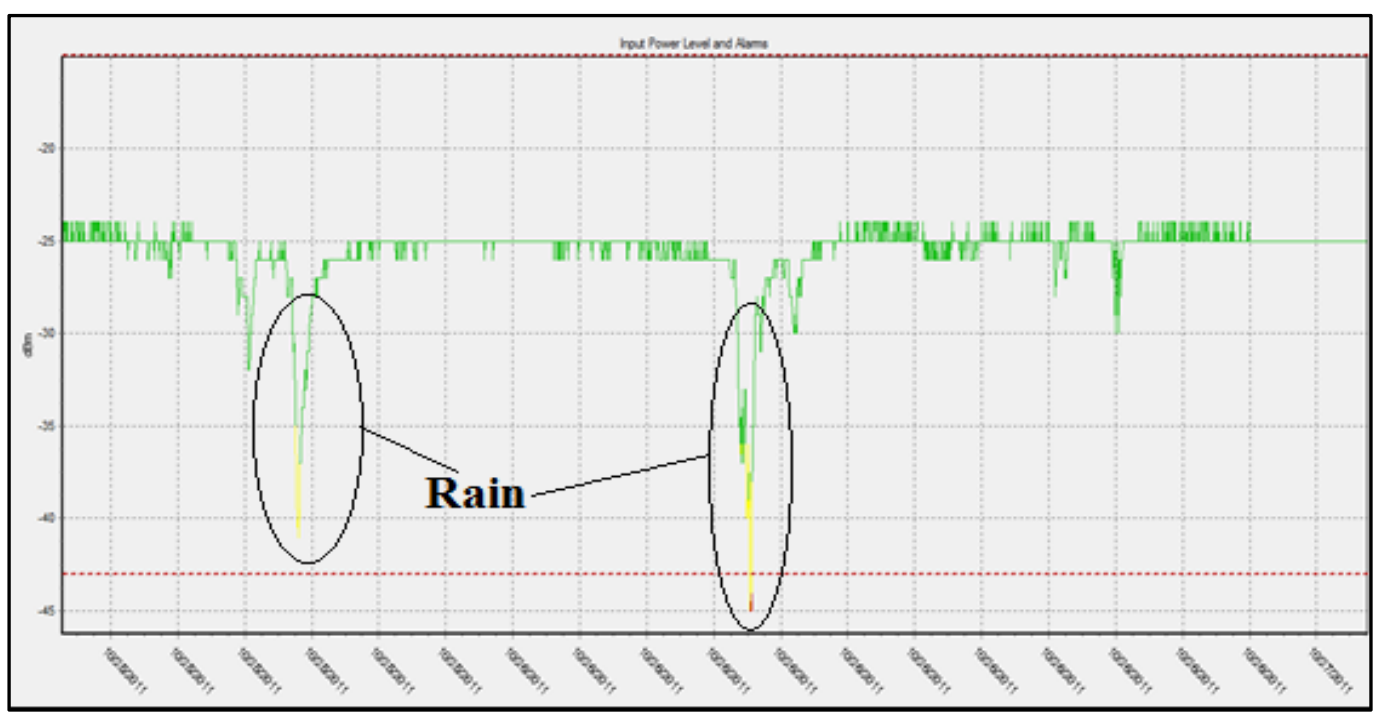

Figure 8: Sample of FSO input power level

Rain data is measured in $\mathrm{mm} / \mathrm{min}$ and will be converted to $\mathrm{mm} / \mathrm{hr}$ as the standard of rain attenuation analysis. On $1^{\text {st }}$ October 2011, rain occurred from 3:44 pm till 4:40 pm. The rain rate during that time is plotted in Fig. 9. Corresponding FSO received signal level is recorded at that time and shown in Fig. 10. Based on the received signal, the actual attenuation is calculated by subtracting the attenuated signal with constant value of the signal level. Then, the synchronization between rain attenuation and FSO signal attenuation is plotted in Fig. 11. From the figure, it obviously confirms that FSO signal will attenuate when there is rain and the attenuation will increase as the rain intensity increases.

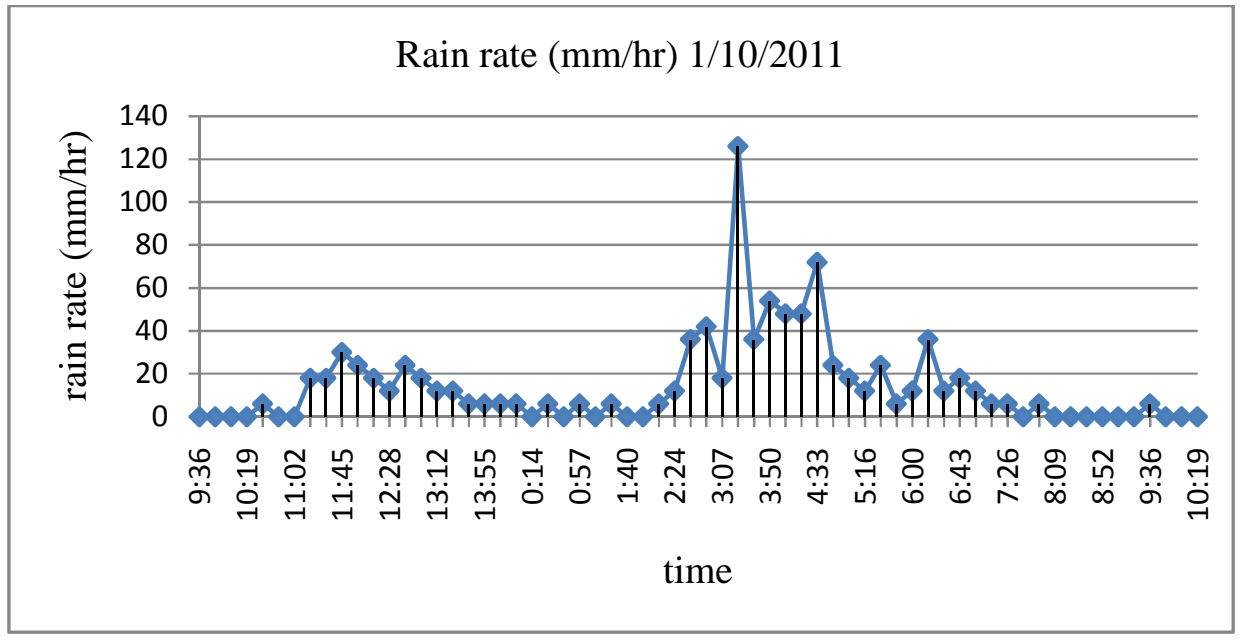

Figure 9: Rain rate data collection for October 1, 2011 


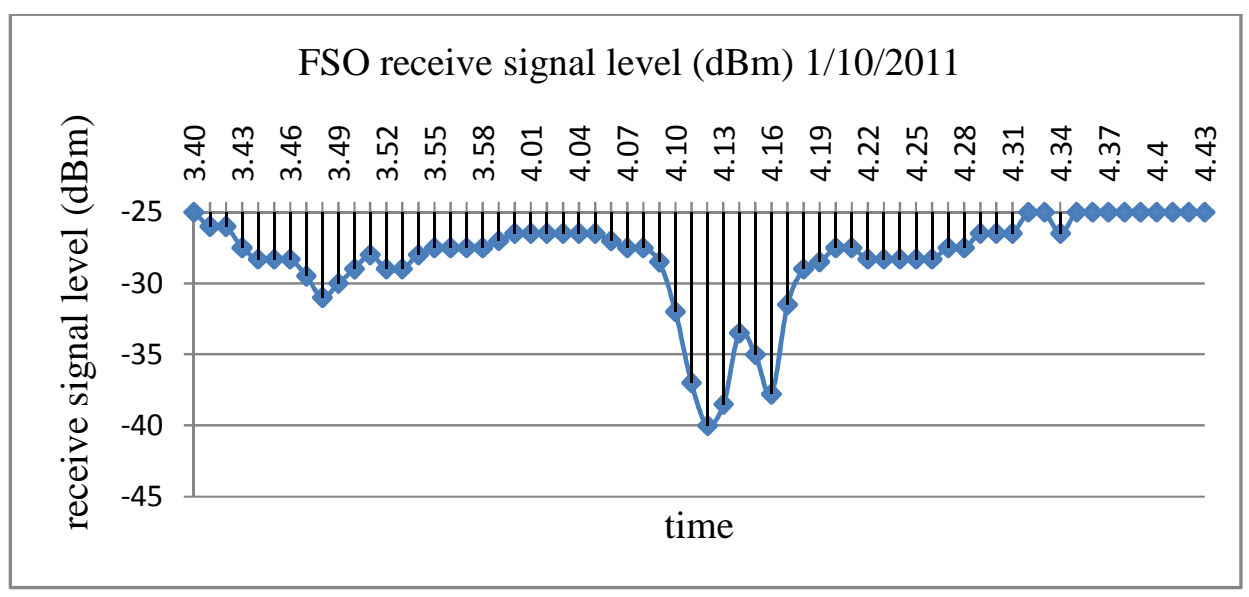

Figure 10: FSO receive signal level for October 1, 2011

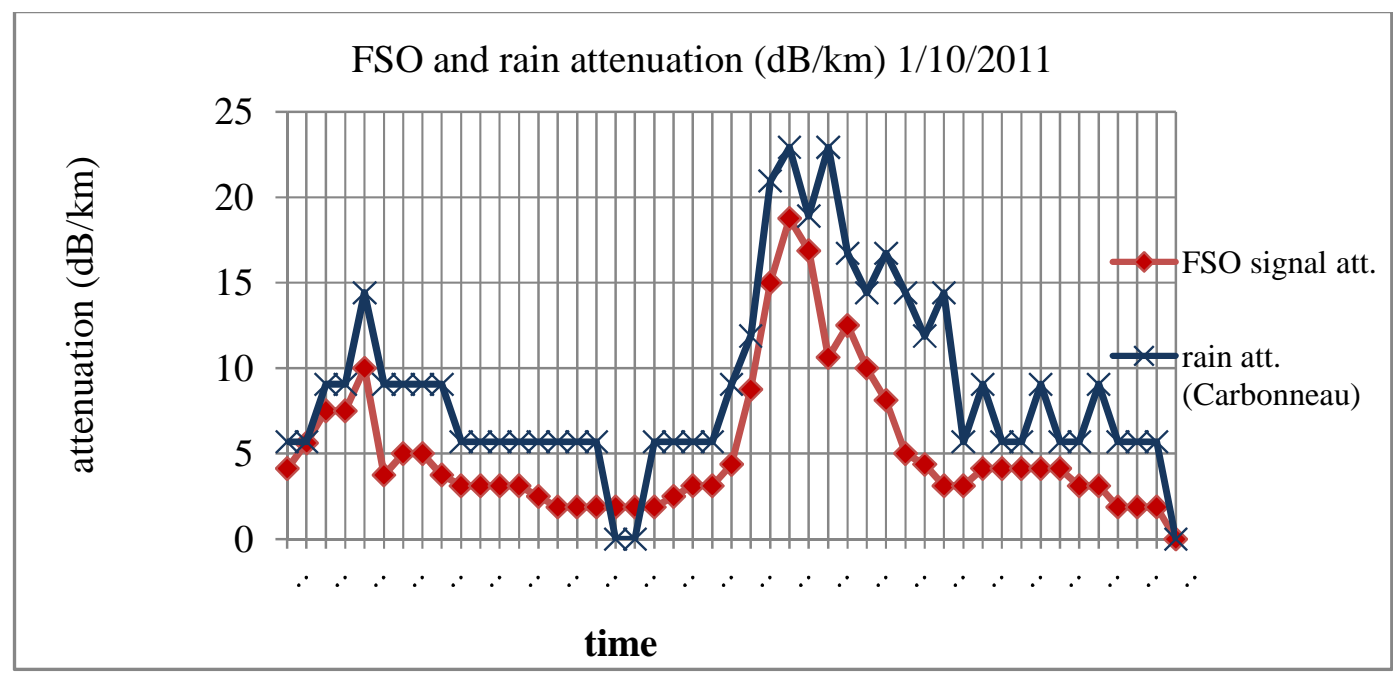

Figure 11: Synchronization data of rain rate and FSO signal attenuation

\subsection{Rain Attenuation Analysis.}

Rain intensity was recorded for one year period which is from January 2011 till December 2011. From the one year data, annualcumulative distribution of measured rain intensity and rain attenuation are obtained. The analysis shows that maximum rain intensity recorded for 2011 is 180 $\mathrm{mm} / \mathrm{hr}$ with percentage of occurrence is $0.0008 \%$ or 0.288 days out of 360 days which is very rare to occur while the lowest rain intensity is $6 \mathrm{~mm} / \mathrm{hr}$ corresponding to $1.16 \%$ of the time. Then, for $0.01 \%$ of an average year, rain intensity is about $110 \mathrm{~mm} / \mathrm{hr}$ which make the difference between ITU-R rain intensity measurement is $35 \mathrm{~mm} / \mathrm{hr}$. Hence, this measurement is important to determine the actual rain intensity occur in Kuala Lumpur to get validate data of link margin. A plot of rain intensity against percentage of time exceeded in a year ranging from 0.001 to $1 \%$ is presented in Fig. 12. 


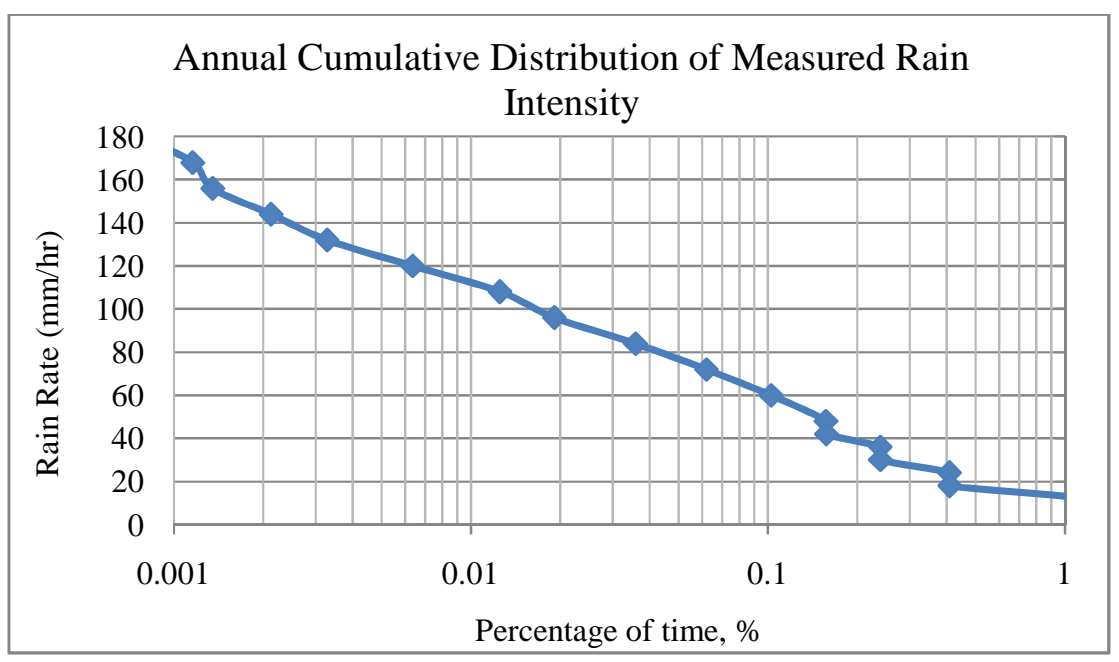

Figure 12: Annual cumulative distribution of measured rain intensity

From the measured rain intensity, specific rain attenuation for terrestrial link is calculated using Eq. (5) and graph for rain attenuation versus percentage of time exceeded is plotted in Fig. 13. It shows that, at $0.01 \%$ of outage or equivalent to $99.99 \%$ availability, attenuation for one kilometre link is approximately $25 \mathrm{~dB}$ or $16 \mathrm{~dB}$ for $0.1 \%$ outage.

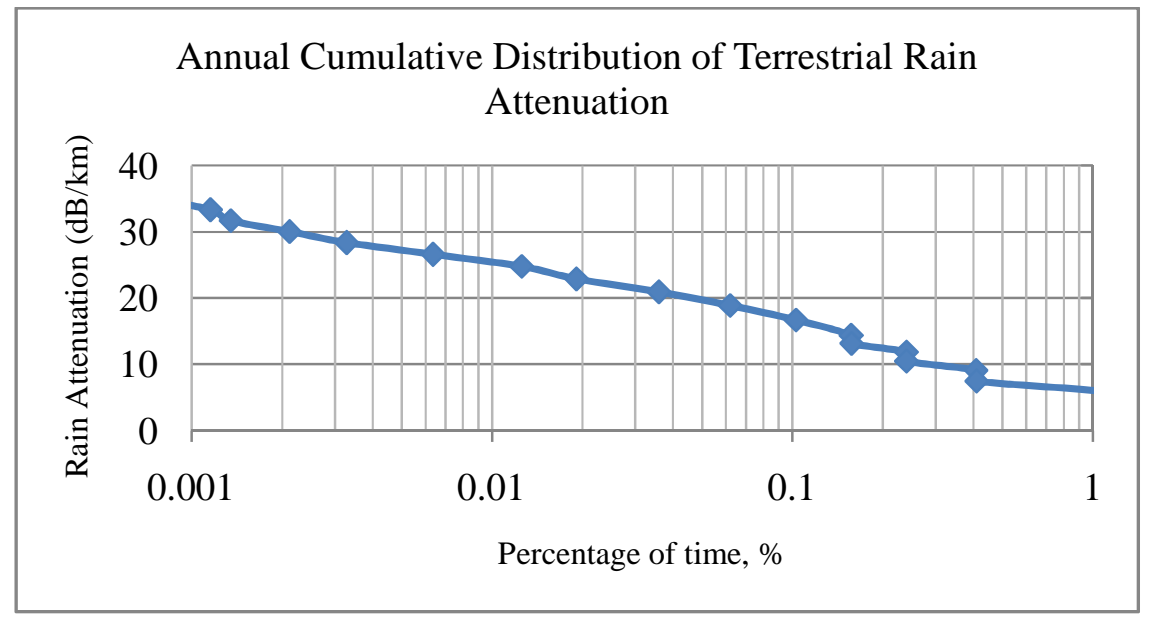

Figure 13: Annual cumulative distribution of rain attenuation

In order to estimate rain attenuation for earth-to-satellite link, rain height or rain effective distance from earth-to-space need to be computed first by using Eq. (8)

Rain effective distance, $L s=\frac{\left(h_{R}-h_{S}\right)}{\sin \theta} \mathrm{km}$

where $h_{R}$ is rain height and $h_{S}$ is height above mean sea level of the earth station in $\mathrm{km}$. By

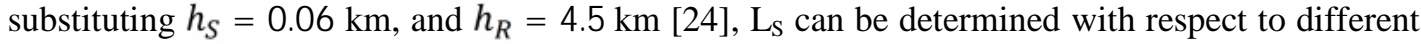
elevation angles. Then, rain attenuation for slant path length can be figured out by multiplying specific rain attenuation for terrestrial with the effective distance of rain height. The rain attenuation for different elevation angles that varies from 10 to 90 degrees was calculated and plotted in Fig 14. This result is compared with the theoretical analysis done using Matlab as 
illustrated in Fig. 15 where three elevation angles are used as the point of references which are 10, 50 , and 90 degrees.

From Fig. 14, we can see clearly the effect of the elevation angle and percentage of time of rain intensity occurrence to the rain attenuation for earth-to-satellite path. The plots indicate that attenuation will decrease as the elevation angle and percentage of outages increases or in other words availability reduces. However, based on the measured rain intensity, the attenuation is lower than the theoretical values. Here, the highest availability that can be achieved by the FSO link is $99.0 \%$ with elevation angle 70 degree. Then, Fig. 15 shows the comparison between theoretical and experimental analysis of slant path rain attenuation at three different elevation angles which are 10, 50 and 90 degree.For instances, at $\theta=90$ degree and $0.1 \%$ of time, the attenuation measured is $74.23 \mathrm{~dB}$ and calculated is $86.36 \mathrm{~dB}$ which make the difference is only $14.05 \%$. Therefore, it can be concluded that, the scaled up data for rain attenuation can be done to estimate the FSO slant path link margin.

Note that for neither theoretical nor experimental result, the link is impossible to establish at $0.001 \%$ of time or $99.999 \%$ availability (5 nines) due to very high attenuation imposed which cannot be mitigated either using very sophisticated system or high transmit power even though most telecommunication system is looking forward to achieve this number. Then, it is considered good if $99.99 \%$ is achievable. However, based on the result, that percentage is also very challenging to achieve as the maximum attenuation imposed is about $650 \mathrm{~dB}$ for 10 degree elevation angle and reduces to $110 \mathrm{~dB}$ at 90 degree elevation angles. The best possible to make the FSO link work is at $1 \%$ of time or lower which the maximum attenuation imposed is $145 \mathrm{~dB}$ which will reduce correspondingly as the elevation reduces. The availability of the link will be discussed further later.

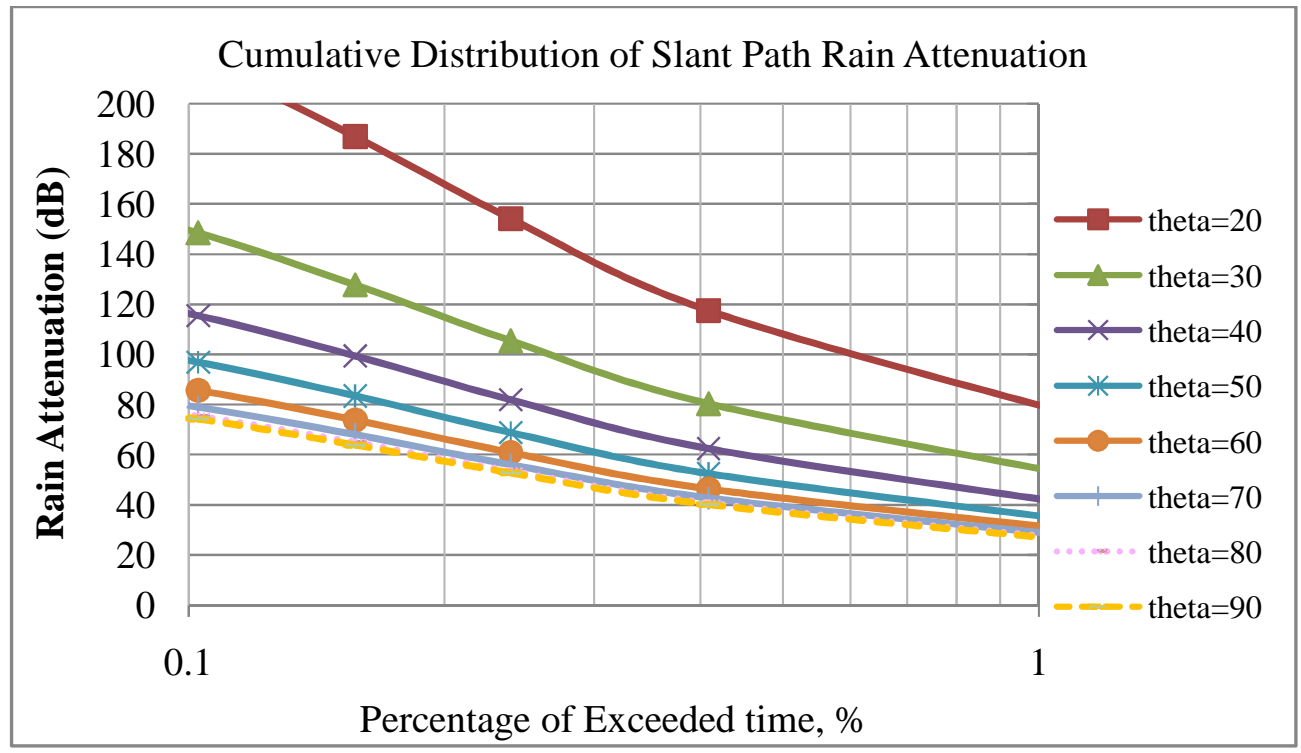

Figure 14: Experimental result of annual cumulative distribution of slant path rain attenuation for various elevation angles 


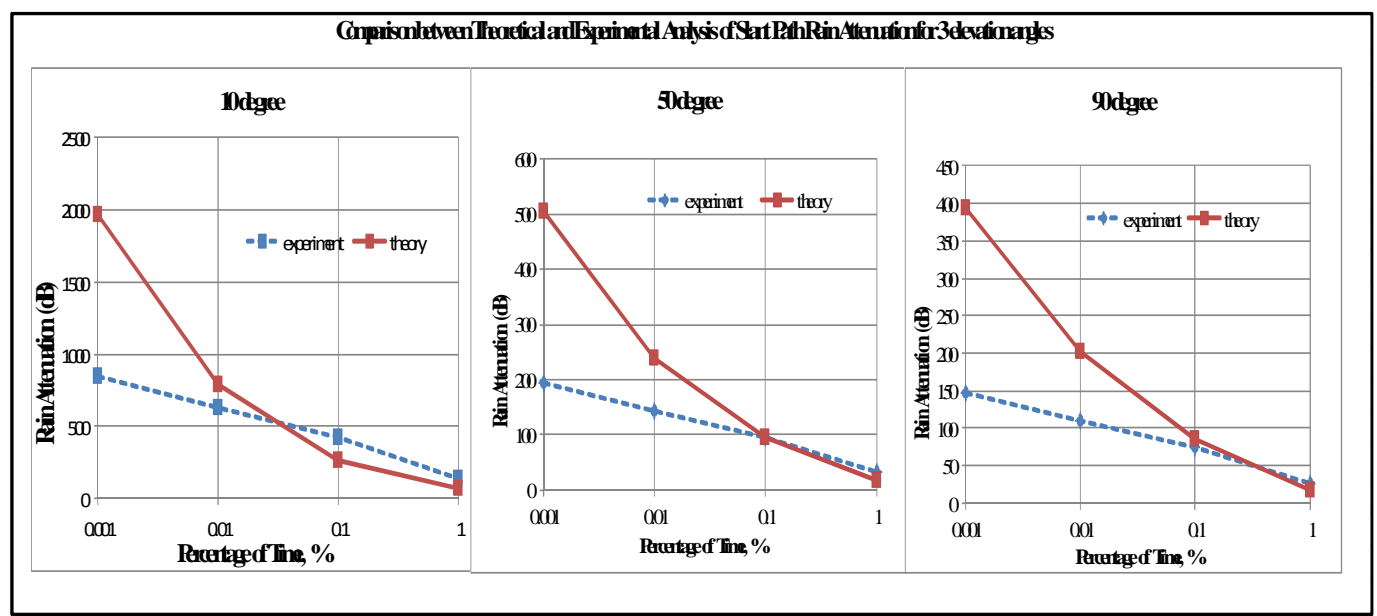

Figure 15: Comparison between theoretical and experimental analysis of slant path rain attenuation at three different elevation angles.

\subsection{Haze Attenuation Analysis}

Haze attenuation is dependent on wavelength, visibility, and measurement distance. In the analysis, wavelength will remain constant at $850 \mathrm{~nm}$ and measurement distance will be varied from 1 to $20 \mathrm{~km}$. However, the distance is considered $20 \mathrm{~km}$ for earth-to-space link corresponding to average depth of troposphere in tropical region [25]. The visibility data is collected for one month which is on February 2012 starting from $3^{\text {rd }}-29^{\text {th }}$ February 2012 . It is assumed that visibility is measured spherically which either terrestrial or slant path link is the same. From the one month data, percentage of time occurrence was computed based on cumulative occurrence of visibility. The measurement shows that the maximum visibility measured is $16 \mathrm{~km}$ which is during clear weather conditions and measured most of the time corresponding to $98.55 \%$ percentage of time of occurrence. While the lowest visibility is measured is $0.23 \mathrm{~km}$ which occurs once in that month corresponding to $0.0026 \%$ or 0.84 hours.

Fig. 16 presents the cumulative distribution of visibility occurrence in February 2012. The figure demonstrates that haze attenuation curve is exponentially growth from $0.001 \%$ to $10 \%$ and constant at V=16 km. While Fig. 17 shows the corresponding haze attenuation based on the percentage of time for 5 different measurements distance which are $1 \mathrm{~km}, 5 \mathrm{~km}, 10 \mathrm{~km}, 15 \mathrm{~km}$, and $20 \mathrm{~km}$. The reason of having several curves for different distances is to validate that the measurement distance will affect the haze attenuation correspondingly with the visibility. But the attention is given to $\mathrm{L}=20 \mathrm{~km}$. Note that, for $0.01 \%$ of time where visibility is about $0.24 \mathrm{~km}$, attenuation due to haze at $\mathrm{L}=20 \mathrm{~km}$ is very high which can be up to $1400 \mathrm{~dB}$ and hence cannot be considered at all. When the percentage is increases to $0.1 \%$, where visibility recorded is $0.65 \mathrm{~km}$ will result to $490 \mathrm{~dB}$ attenuation at $\mathrm{L}=20 \mathrm{~km}$. However, this number is still high is any telecommunication system. Hence, consideration can be made for $1 \%$ percentage of time equivalents to $\mathrm{V}=4.54 \mathrm{~km}$ and haze attenuation is drop to only $55 \mathrm{~dB}$. If better performance is required, percentage of $10 \%$ and more should be contemplation as at that percentage, the atmosphere is almost in clear weather condition with attenuation is approximately $12 \mathrm{~dB}$. 


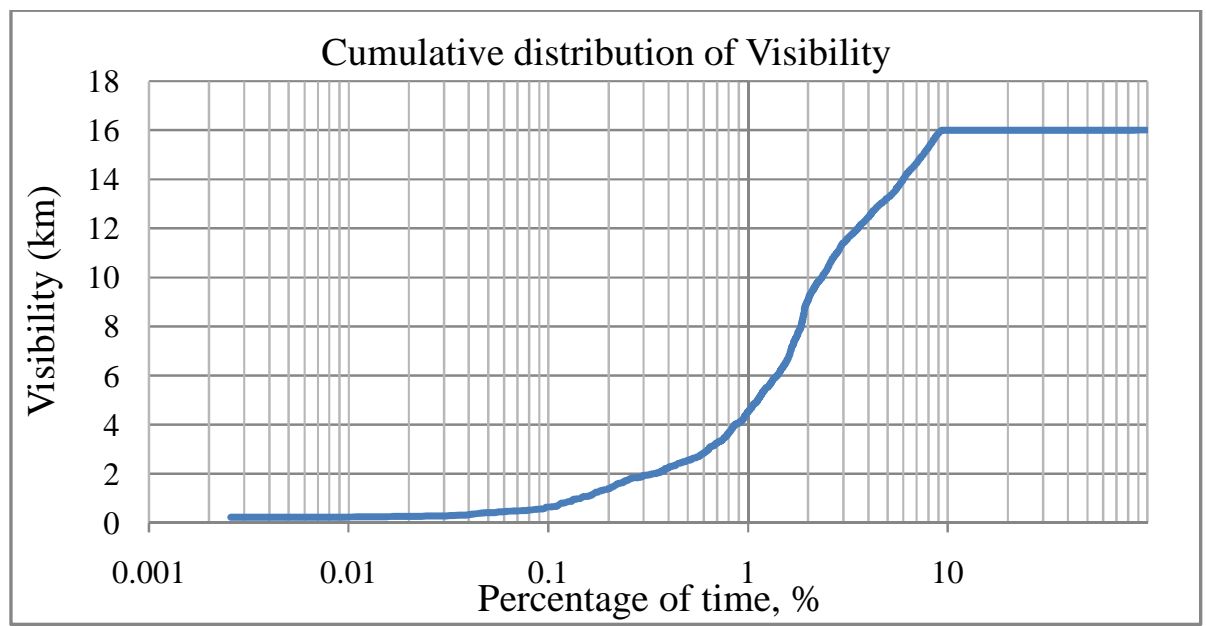

Figure 16: Cumulative distribution of visibility for one month period

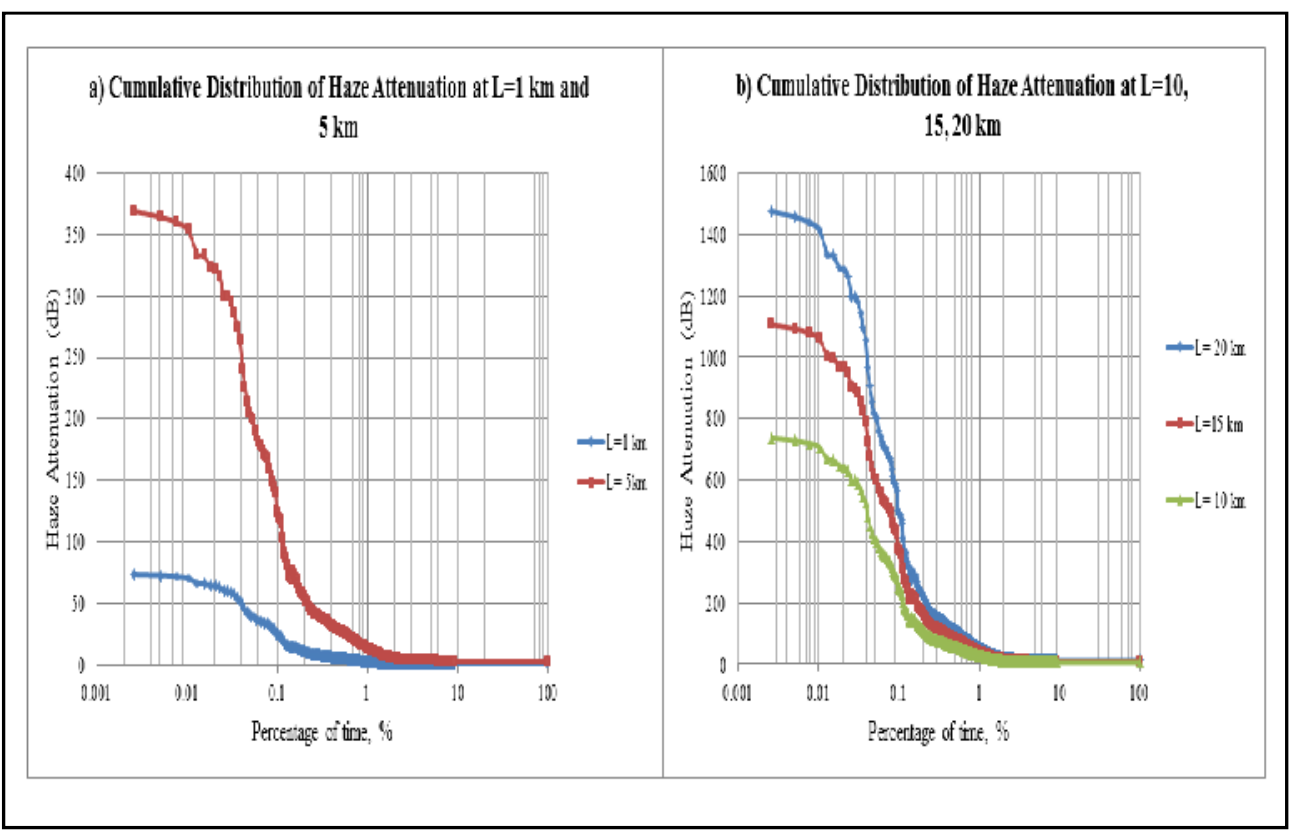

Figure 17: Cumulative distribution of haze attenuation at different measurements distances

Next, Fig. 18 demonstrates haze attenuation with respect to different percentage of time and elevation angles where the measurement distance is fixed to $20 \mathrm{~km}$. The graphs validate that elevation angles is important element in defining any attenuation when involving slant path link. It is noted that, attenuation decreases when elevation angles and percentage of time increases. As for the example, at $1 \%$ percentage of time, haze attenuation will increase up to $300 \mathrm{~dB}$ at 10 degree elevation angle and can be about $60 \mathrm{~dB}$ at 90 degree elevation angle. While at $10 \%$ percentage of time, haze attenuation is in the range of 12 to $70 \mathrm{~dB}$ for all elevation angles. Hence, elevation angle and percentage of time need to be carefully chosen in determining an operational FSO link from earth-to-satellite. 


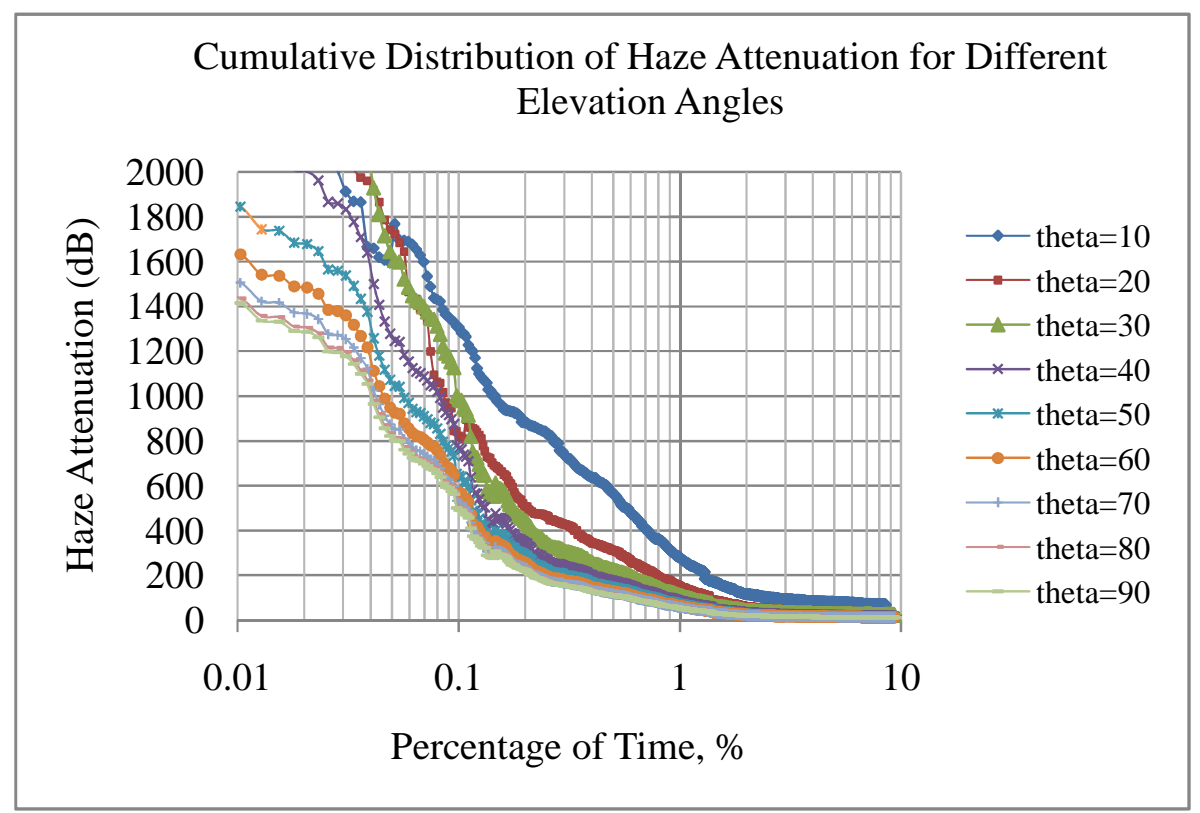

Figure 18: Cumulative distribution of slant path haze attenuation for different elevation angles

\subsection{Total Attenuation, Link Availability, and Link Margin.}

Total losses are calculated based on two events which are during rainy event and hazy conditions. The losses are summation from geometrical attenuation, absorption, scintillation and rain attenuation or haze attenuation. For the references, beam divergence angle is set to $0.1 \mathrm{mrad}$ and with 10 times differences (e.g. 0.01 and $1.0 \mathrm{mrad}$ ), the attenuation will increase or reduce about $20 \mathrm{~dB}$. All the losses are calculated separately for different elevation angles as it will give a major impact to the total losses.The other fixed parameters are transmitted wavelength which is $850 \mathrm{~nm}$ and receiver capture surface where the diameter is equivalent to $0.32 \mathrm{~m}$. These parameters are based on the FSO equipment used in the experimental works.

Then, based on total attenuation calculated, link availability can be estimated by measuring the power received signal. At this point, transmitted power and receiver sensitivity can be adjusted to make it compatible with the losses incurred. Since the total attenuation is quite high during rain and haze, the transmitted power and sensitivity value are set to maximum to combat the total attenuation occurred during the signal transmission. According to[8], the highest conceivable transmit power that a FSO system could use is $10 \mathrm{~W}$ or $40 \mathrm{dBm}$ while receiver sensitivity is set to $-90 \mathrm{dBm}$. After that, link margin will be computed.

\subsubsection{FSO Link Performance during Rainy Events}

Fig. 19 shows the total attenuation versus elevation angles at different percentages of time for 0.1 mrad beam divergence angle during rainy events. At $0.01 \%$ of time exceed or $99.99 \%$ availability, FSO system needs to combat the attenuation from $158 \mathrm{~dB}$ to $700 \mathrm{~dB}$ depends on the elevation angle used in order to establish the link. From that range of attenuation, it seems that it is impossible to transmit the data from ground to space. Hence, higher percentages of time need to be considered. Then, at $0.1 \%$ of time, the total attenuation is lower than $200 \mathrm{~dB}$ at $\theta>40$ degree and can be negotiated. While the best performance is at $99.0 \%$ availability or $1.0 \%$ of outage with the range of attenuation is in between 73-213 dB. 


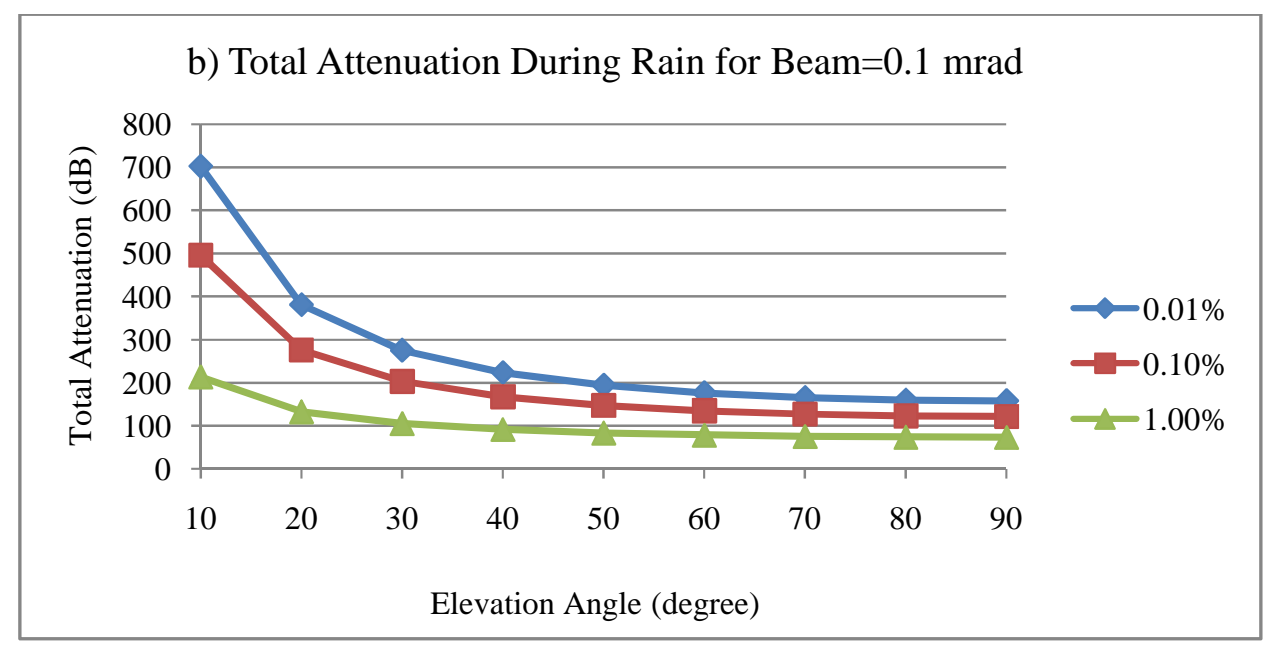

Figure 19:Total attenuation during rainy events versus elevation angle for different percentages of time at $\varphi=0.1 \mathrm{mrad}$.

From the total attenuation, link availability is estimated. Fig. 20 illustrates the power received versus availability for different elevation angles at $\varphi=0.1 \mathrm{mrad}$ during rainy events. The link is established when the power received is higher than sensitivity value. The figure validates that $99.99 \%$ availability is never achievable even though $\theta$ is lower down to 10 degree. At $99.0 \%$ availability, the link is successfully achieved at $\theta=30$ degree and above.

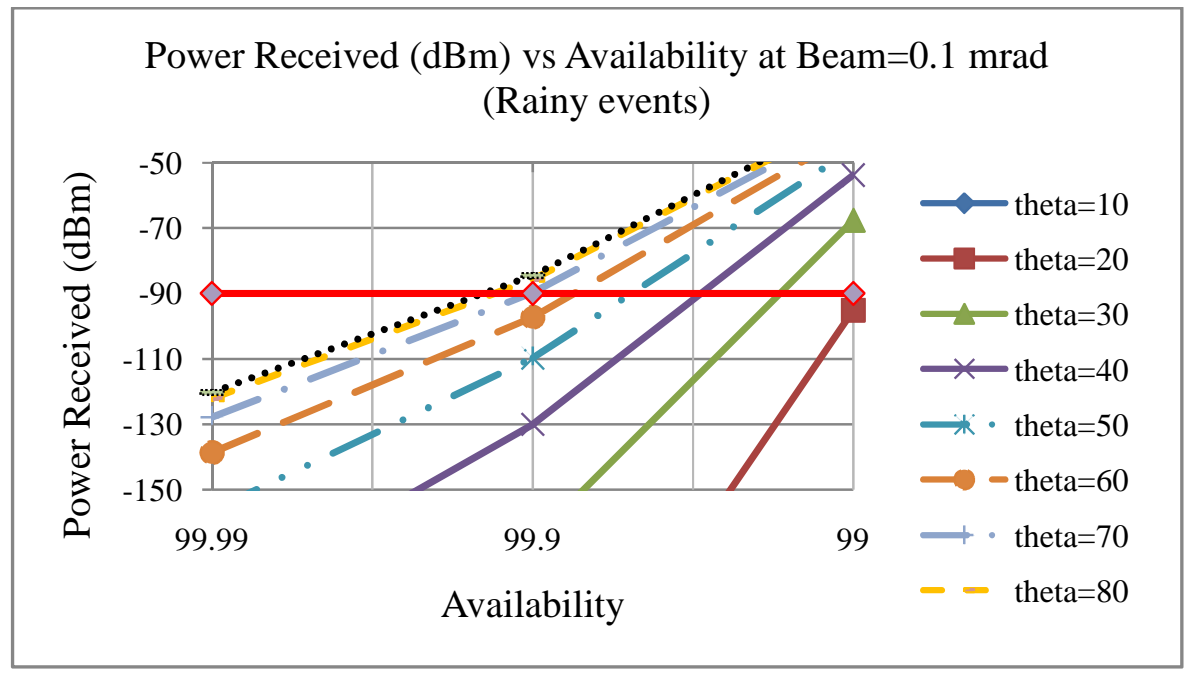

Figure 20: Power received vs availability for different elevation angles during rainy event at $\varphi=0.1 \mathrm{mrad}$.

Based on the link availability evaluation, the best achievable FSO link from earth-to-satellite is at $99.0 \%$. Hence, the link margin will be estimated at $99.0 \%$ availability at $\varphi=0.1 \mathrm{mrad}$ and $\theta=50$ degree. Table 2 shows the specific calculation of link margin for FSO link from earth-to-satellite with the distance of $750 \mathrm{~km}$. From that computation, link margin during rainy event at $99.0 \%$ availability is approximately $44.28 \mathrm{~dB}$ by suffering $85.72 \mathrm{~dB}$ losses. 
International Journal of Computer Science, Engineering and Applications (IJCSEA) Vol.3, No.1, February 2013

Table 2: Link margin analysis for FSO link from earth-to-satellite during rainy event at $99.0 \%$ availability

\begin{tabular}{|l|c|c|}
\hline \multicolumn{1}{|c|}{ Parameter } & Unit & Value \\
\hline Wavelength & $\mathrm{nm}$ & 850 \\
\hline Link Distance & $\mathrm{km}$ & 750 \\
\hline Receiver Diameter & $\mathrm{m}$ & 0.32 \\
\hline Transmit Divergence Angle & $\mathrm{mrad}$ & 2 \\
\hline Elevation Angle & $\mathrm{degree}$ & 50 \\
\hline Transmit Power & $\mathrm{dBm}$ & 40 \\
\hline Receiver Sensitivity & $\mathrm{dBm}$ & -90 \\
\hline System Loss & $\mathrm{dB}$ & 2 \\
\hline Geometrical Loss & $\mathrm{dB}$ & 49.71 \\
\hline Absorption & $\mathrm{dB}$ & 0.95 \\
\hline Rain Attenuation & $\mathrm{dB}$ & 32.96 \\
\hline Scintillation & $\mathrm{dB}$ & 0.104 \\
\hline Total Loss & $\mathrm{dB}$ & 85.724 \\
\hline Link Margin & $\mathrm{dB}$ & 44.276 \\
\hline
\end{tabular}

\subsubsection{FSO Link Performance during Hazy Conditions}

Next, performance during hazy conditions is evaluated. Fig. 21 shows the total attenuation versus elevation angles at different percentages of time for $\varphi=0.1 \mathrm{mrad}$. During hazy conditions, the attenuation is higher than rainy events and therefore higher percentages of time are contemplated which are $0.1 \%, 1 \%$ and $10 \%$. At $0.1 \%$, the total attenuation is really high which up to $2900 \mathrm{~dB}$ which intolerable to achieve. Even though the percentage of time is reduces to $1.0 \%$, the link is achievable at $\theta>30$ degree only where attenuation is less than $200 \mathrm{~dB}$. Better expected is at $90 \%$ availability or $10 \%$ outage where the attenuation is in the range $60-140 \mathrm{~dB}$.

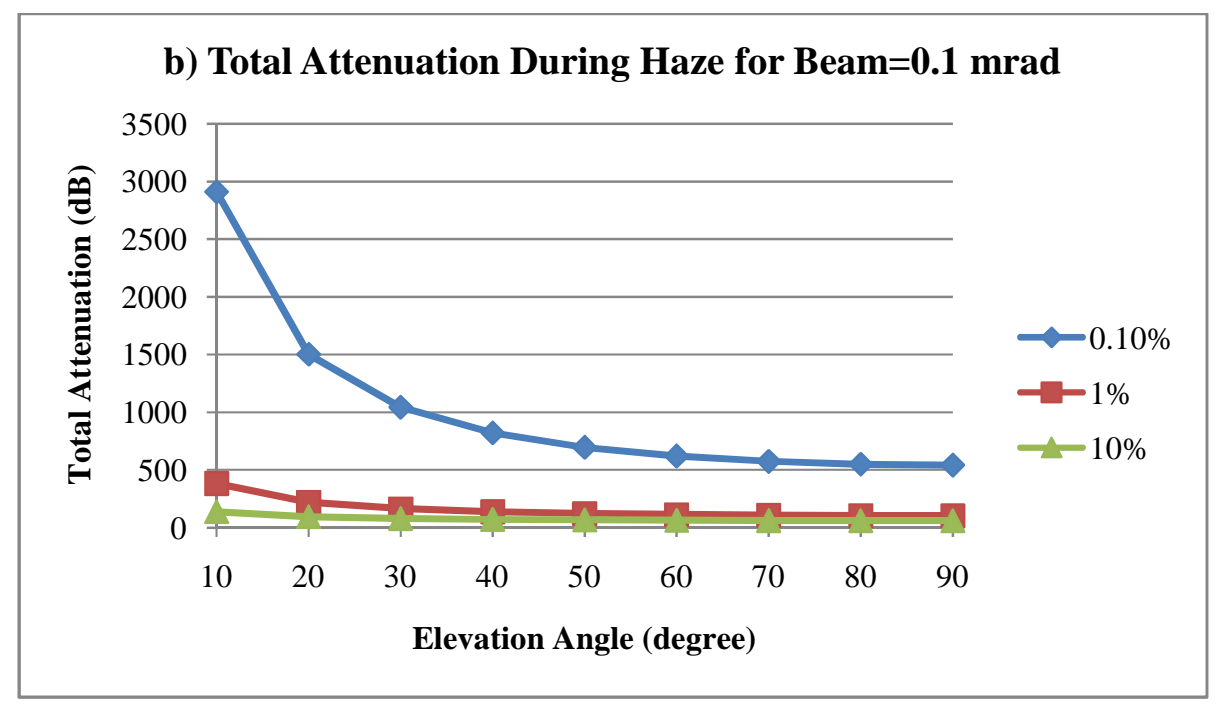

Figure 21: Total attenuation vs elevation angle for different percentages of time at $\varphi=0.1 \mathrm{mrad}$.

Then, Fig. 22 demonstrates power received versus link availability during hazy condition with respect to different elevation angles at $\varphi=0.1 \mathrm{mrad}$. From the figure, the maximum link availability could be achieved is at $99 \%$ with $\theta>50$ degree. Better choice is at $95 \%$ availability 
with minimum elevation angle of 20 degree. 10 degree elevation angle is never achieved for all availability listed.

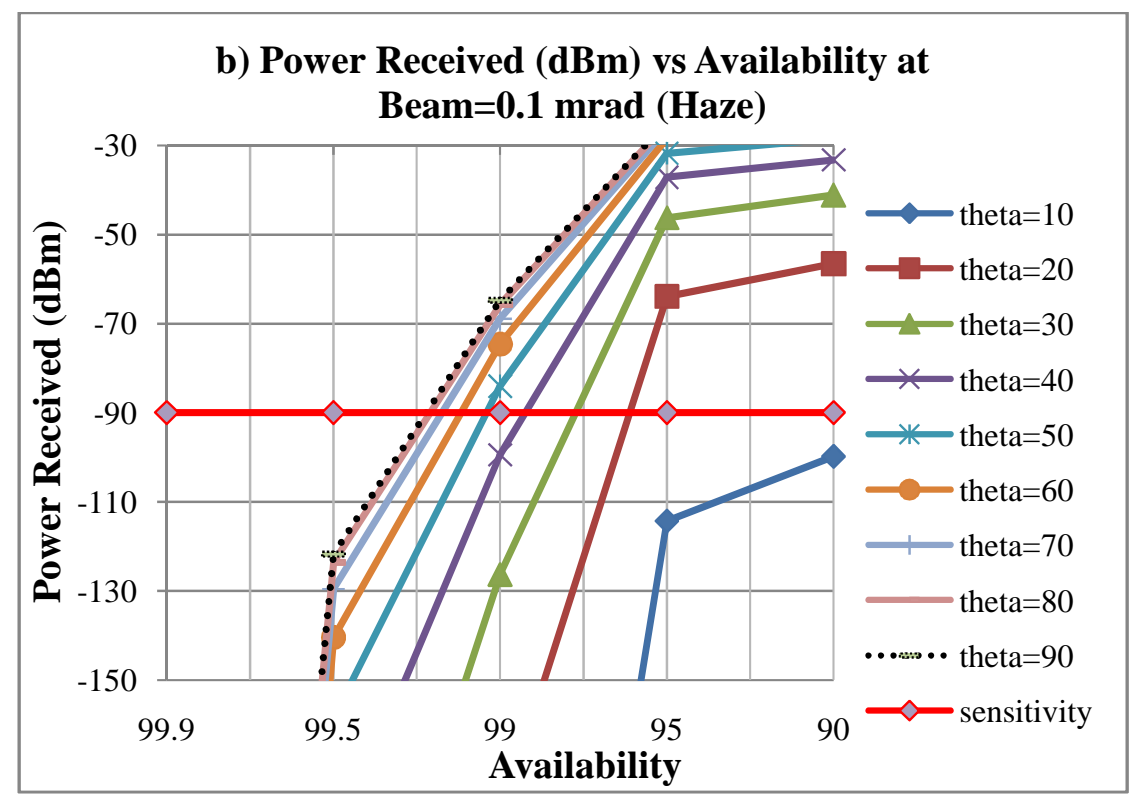

Figure 22: Power Received vs Availability for different Elevation Angles during Hazy Conditions at $\varphi=0.1$ mrad.

Last but not least, link margin for hazy conditions is evaluated. During hazy conditions, the link suffered terribly at very low elevation angles such as 10 and 20 degree. But the loss will be reduced significantly when elevation angle increases. The analysis will be evaluated for $95 \%$ availability or equivalent to $15 \%$ of time exceeded. Table 3 presents the link margin at $5.0 \%$ of time exceeded at $\varphi=0.1 \mathrm{mrad}$ and $\theta=50$ degree. Here, loss due to haze contribute about $19.01 \mathrm{~dB}$ which make the total losses is about $71.77 \mathrm{~dB}$. With that loss, link margin for the FSO link is $58.23 \mathrm{~dB}$. But absolutely link margin will be lower when higher availability is selected.

Table 3: Link margin analysis for FSO link from earth-to-satellite during hazy condition at 5.0\% of time exceeded

\begin{tabular}{|l|c|c|}
\hline \multicolumn{1}{|c|}{ Parameter } & Unit & Value \\
\hline Wavelength & $\mathrm{nm}$ & 850 \\
\hline Link Distance & $\mathrm{km}$ & 750 \\
\hline Receiver Diameter & $\mathrm{m}$ & 0.32 \\
\hline Transmit Divergence Angle & $\mathrm{mrad}$ & 0.1 \\
\hline Elevation Angle & degree & 50 \\
\hline Transmit Power & $\mathrm{dBm}$ & 40 \\
\hline Receiver Sensitivity & $\mathrm{dBm}$ & -90 \\
\hline System Loss & $\mathrm{dB}$ & 2 \\
\hline Geometrical Loss & $\mathrm{dB}$ & 49.71 \\
\hline Absorption & $\mathrm{dB}$ & 0.95 \\
\hline Haze Attenuation & $\mathrm{dB}$ & 19.01 \\
\hline Scintillation & $\mathrm{dB}$ & 0.104 \\
\hline Total Loss & $\mathrm{dB}$ & 71.774 \\
\hline Link Margin & $\mathrm{dB}$ & 58.226 \\
\hline
\end{tabular}




\section{CONCLUSION}

Atmospheric effects are the main challenge to design any FSO links as the transmission channel is air. This paper is analysing the availability of the FSO links from earth-to-satellite by quantifying several atmospheric effects in Malaysia. Rain and haze were measured on terrestrial FSO links located in IIUM. Measured rain intensity, visibility range and received signal levels on FSO link data were scaled up to estimate earth-to-satellite link's fade margin and availabilities. The atmospheric absorption, scintillation and geometrical attenuation were also estimated based on prediction models. Analysis done based on various beam divergence angles and elevation angles. From the analysis of $0.1 \mathrm{mrad}$ beam divergence angle, it is found that earth-to-satellite FSO link is feasible to establish at $99.0 \%$ availability during rainy events with $44.28 \mathrm{~dB}$ margin and elevation angle of 50 degree. During hazy conditions, it is suggested to have $95 \%$ availability with elevation angle must be higher than 20 degree as $58.23 \mathrm{~dB}$ margin is obtained for 50 degree elevation angle. All the result could be a benchmark of having an operational FSO link from earth-to-satellite in tropical regions.

\section{REFERENCES}

[1] O. Bouchet, H. Sizun, C. Boisrobert, F. d. Fornel, and P.-N. Favennec, Free-Space Optics: Propagation and Communication 1ed. USA: Wiley-ISTE, 2006.

[2] E. Leitgeb, M. Gebhart, and U. Birnbacher, "Optical networks, last mile access and applications," in Free Space Laser Communications: Priciples and Advances, vol. 2, 2005, pp. 273-302.

[3] M. Toyoshima, K. Takizawa, T. Kuri, W. Klaus, M. Toyoda, K. Suzuki, T. Takahashi, S. Kimura, H. Kunimori, T. Jono, Y. Takayama, and K. Arai, "An overview of the KODEN experiment between the OICETS satellite and the optical ground station in NICT," Elektrotechnik und Informationstechnik, vol. 124, pp. 193-199, 2007.

[4] M. Toyoshima, "Trends in Laser Communications in Space," November 2010.

[5] S. Bloom, E. Korevaar, J. Schuster, and H. Willebrand, "Understanding the performance of free-space optics " Journal of Optical Networking, vol. 2, pp. 178-200 2003.

[6] ITU-R, "RECOMMENDATION ITU-R P.1814, Prediction methods required for the design of terrestrial free-space optical links ", 2007.

[7] ITU-R, "RECOMMENDATION ITU-R P.1622. Prediction methods required for the design of Earthspace systems operating between $20 \mathrm{THz}$ and $375 \mathrm{THz}, 2003$.

[8] I. I. Kim and E. Korevaar, "Availability of Free Space Optics (FSO) and hybrid FSO/RF systems," Proc. SPIE Optical Wireless Communication IV, vol. 4530, pp. 84-95, 2001.

[9] ITU-R, "RECOMMENDATION ITU-R P.1621-1, Propagation data required for the design of Earthspace systems operating between $20 \mathrm{THz}$ and $375 \mathrm{THz}, " 2005$.

[10] H. Willebrand and B. Ghuman, Free Space Optics: Enabling Optical Connectivity in Today's Networks, 1 ed. US: Sams Publishing, 2001.

[11] ITU-R, "Recommendation ITU-R P.837-4 Characteristics of precipitation for propagation modeling," 2003.

[12] J. Louis J. Ippolito, "Transmission Impairments," in Satellite Communication Systems Engineering: Atmospheric Effects, Satellite Design, and System Performance: John Wiley \& Sons, 2008, pp. 89138.

[13] T. H. Carbonneau and D. R. Wisely, "Opportunities and challenges for optical wireless; the competitive advantage of free space telecommunications links in today's crowded market place," SPIE Conference on optical wireless communications, pp. 119-128, 1998.

[14] ITU-R, "RECOMMENDATION ITU-R P.618-10, Propagation data and prediction methods required for the design of Earth-space telecommunication systems," 2009.

[15] M. Achour, "Simulating Atmospheric Free-Space Optical Propgation, Part II: Haze, Fog, and Low Clouds Attenuations," Proceeding of SPIE vol. 4873, 2002.

[16] I. I. Kim, B. McArthur, and E. Korevaar, "Comparison of laser beam propagation at $785 \mathrm{~nm}$ and $1550 \mathrm{~nm}$ in fog and haze for optical wireless communications," Proc. SPIE Optical Wireless Communication III, vol. 4214, 2000.

[17] MMD, "http://www.met.gov.my."

[18] Haze-Watch, "http://haze.asean.org/index.php." 
[19] FSO, "FlightStratahttp://www.fso.com.my/flight_strata.php."

[20] "RM Young Tipping Bucket Rain Gauge http://www.youngusa.com/products/3/18.html."

[21] Nexsens, "http://nexsens.com/products/nexsens_isic_datalogger.htm."

[22] A. Soleiman, M. Othman, A. A. Samah, N. M. Sulaiman, and M. Radojevic., "The Occurence of Haze in Malaysia: A Case Study in an Urban Industrial Area," Pure and Applied Geophysics, vol. 160, pp. 221-238, 2003.

[23] K. Badron, A. F. Ismail, J. Din, and A. R. Tharek, "Rain induced attenuation studies for V-band satellite communication in tropical region," Journal of Atmospheric and Solar-Terrestrial Physics, vol. 73, pp. 601-610, 2011.

[24] ITU-R, "RECOMMENDATION ITU-R P.839-3 Rain height model for prediction methods," 2001.

[25] Wikipedia, "http://en.wikipedia.org.wiki/Troposphere," n. d.

\section{AUTHORS}

Norhanis Aida M. Nor received BSc. Degree in Communication Engineering from International Islamic University Malaysia (IIUM), Malaysia in 2009. After graduated, she joint MIMOS-IIUM student attachment program in developing FSO-QKD project. Currently, she is a full-time master degree student at IIUM and expected to complete her study in Jun 2012. Her areas of interest are free space optics and microwave communications.

Md. Rafiqul Islam received his BSc (Electrical and Electronic Engineering) from BUET, Dhaka in 1987. He received his MSc and PhD both in Electrical Engineering from UTM in 1996 and 2000 respectively. He is Fellow of IEB and member of IEEE. He is currently an associate professor at Electrical and Computer Engineering Department of International Islamic University Malaysia. His areas of research interest are wireless channel modeling, radio link design, RF propagation measurement and modeling, RF design, and smart antennas.

WajdiFawzi Mohammed Al-Khateeb received his PhD from the International Islamic University (IIUM), Malaysia in 2006 and his MSc from the Technical University of Berlin, Germany in 1968. His research interest is mainly in the Reliability Engineering, Fault Tolerant Systems, QoSNetworking, Microwave Radio Links. He is currently an assistant Professor in the department of Electrical and Computer Engineering, IIUM. Beside his academic activity, he was appointed as leader of consultancy team to plan, design, and supervises the ICT infrastructure project with more than 30 thousand data/voice nodes to support the ICT applications of the University.

Suriza Ahmad Zabidi obtained her BSc degree in electrical engineering from George Washington University, Washington DC. Then, she completed her master degree in computer engineering in IIUM, Malaysia and currently she is pursuing her $\mathrm{PhD}$ degree at the same university in Free Space Optics. Her areas of interest are Free Space Optic, Biometrics-based System, Electronics, and Circuit Design.
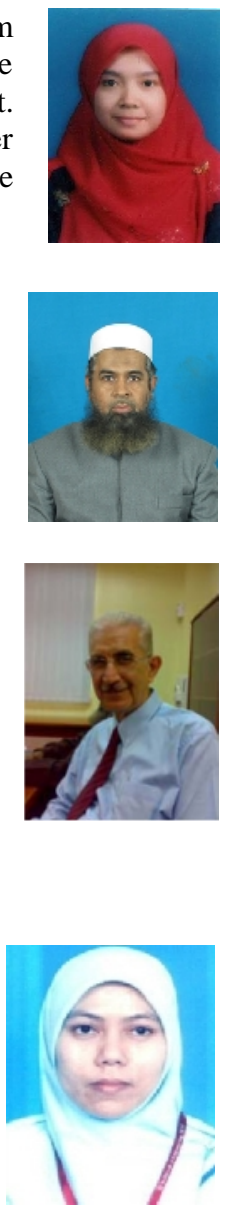